B. APL, 42. $2006(201-205)$

\title{
DISCURSO DE RECEPCIÓN EN LA INCORPORACIÓN DEL ACADÉMICO SALOMÓN LERNER FEBRES
}

\author{
Ricardo Silva-Santisteban Ubillús
}

Señor Doctor Marco Martos, Presidente de la Academia Peruana de la Lengua.

Señores Académicos

Señoras y Señores

La Academia Peruana de la Lengua se ha reunido esta noche en sesión pública para incorporar como uno de sus miembros a Salomón Lerner Febres, para lo cual me ha concedido el honor de presentarlo dentro del corazón de esta institución.

Varias son las facetas de la persona y de las obras de quien, como Salomón Lerner Febres, optó en su juventud por el estudio de la Filosofía, es decir la rama del saber dedicada al estudio del conjunto del conocimiento universal, pero que busca organizar sus principios generales de una manera racional. Necesariamente, pues, la Filosofía en algún momento linda con lo ideológico y la manera de concebir el mundo y, si es que procede, con lo divino.

Como intelectual y estudioso, Salomón Lerner Febres es autor de diversos estudios y ensayos que se encuentran dispersos en distintas revistas académicas y que están a la espera de su recopilación en libro. Constituyen 
el testimonio de su dedicación al estudio de la filosofía principalmente moderna de autores como Friedrich Nietzsche, Martin Heidegger o Emmanuel Levinas. Los dedicados a Heidegger son ejemplares y penetrantes y conforman, de por sí, un volumen separado. Muchos otros se encuentran dedicados, además de temas filosóficos, a temas humanísticos en los que resplandece su amor a la justicia, al saber y a la solidaridad humana. Gran parte de sus estudios y meditaciones, que aún permanecen inéditos, han sido expuestos en prestigiosos foros internacionales distribuidos en cuatro de los cinco continentes del planeta.

Aunque la actividad intelectual de Salomón Lerner Febres se ha desarrollado en varias universidades y centros de altos estudios, su labor principal se encuentra vinculada sobre todo con la Pontificia Universidad Católica del Perú, donde realizó sus estudios, obtuvo alguno de sus títulos y donde se ha dedicado durante largos e intensos años a la enseñanza de distintas materias como la filosofía moderna, la metafísica, la epistemología, la teoría del conocimiento, la antropología filosófica y la antropología religiosa, entre otras.

Su carrera universitaria se ha desarrollado también en múltiples trabajos en los que colindan lo académico con lo administrativo. Así, ha sido varias veces Decano, Jefe de Departamento, Director Académico de Investigación, Miembro del Consejo Universitario, Vicerrector y, finalmente, Rector de la Pontificia Universidad Católica del Perú durante dos fecundos períodos que van de 1994 a 2004 en los que le tocó colocar a este centro de estudios como una de las Universidades de mayor prestigio nacional a nivel continental y mundial. En reconocimiento a esta labor excepcional, la nueva administración de la Pontificia Universidad Católica del Perú le otorgó el título de Rector Emérito en noviembre de 2004, caso único, hasta donde se me alcanza, entre las Universidades del país.

Desde el benemérito Platón se acusa a la Filosofía de encontrarse en constante disputa con la Poesía. El pleito se explica quizá por ese choque de Razón e Imaginación que por lo general les da forma. Pero esta disputa no es tan absoluta y tan cierta ya que entre la Poesía, la más grande de las artes según Stéphane Mallarmé, y la Filosofía, la expresión más acabada y profunda 
del pensamiento, ha habido, cuando menos esporádicamente, buenas relaciones ya que, no pocas veces, los poetas han sido los difusores del pensamiento filosófico de su época como en el caso de Lucrecio, Dante o Shelley. Por otro lado, muchos grandes e inteligentes filósofos han construido sus sistemas de pensamiento impulsados y apoyados en las alas de la Poesía, como en el caso de Platón, Nietzsche o Santayana.

Por mi parte, me place testimoniar el acercamiento de Salomón Lerner Febres desde la ribera de la Filosofía hacia la cordial ribera de la Poesía para resaltar su fructífera frecuentación que se testimonia en el estilo de su escritura.

Como su maestro Heidegger, que dedicó importantes estudios a la poesía de Hölderlin, Trakl o Stefan George, Salomón Lerner Febres ha dedicado un ejemplar estudio a la poesía de nuestro recordado poeta y académico, desaparecido hace dos años, Javier Sologuren. Desde la ribera de la filosofía ha sabido penetrar con singular hondura en esta poesía para cuya apreciación se requiere además condiciones de buen gusto.

En el ámbito de las publicaciones, mencionaré solo dos de las más importantes relacionadas con la Poesía: la primera edición de las Obras completas de César Vallejo uno de nuestros poetas más importantes, en catorce tomos, y las Obras completas de Javier Sologuren, en diez. Si ahora podemos consultarlas y, seguramente en lo futuro, mejorarlas no hay que olvidar que se deben gracias a su decisión, a su concurso y a su constante apoyo.

Entre las diversas actividades realizadas por Salomón Lerner Febres a lo largo de su fecunda vida, he dejado para el final la del rol capital que le tocó en su actuación como Presidente de la Comisión de la Verdad y de la Reconciliación cuya labor se resume, se concentra y se decanta en los nueve apabullantes tomos de su Informe Final. Obra esta de carácter interdisciplinario en la que se cruzan la Historia, la Sociología, la Economía, la Política, la Psicología, la Antropología, etc. y que se erguirá en las décadas futuras como un monumento acusador de la imposibilidad de los peruanos para constituirse, hasta el día de hoy, como una nación integrada por la carencia de verdaderos y positivos conductores de su destino y por las fuerzas oscuras que han anidado siempre tras los velos del poder. 
En un momento en que la República debía reflexionar y hacer el recuento de su discurrir por la historia reciente, que se había enlutado con víctimas numerosas y por la que habían campeado intereses encontrados, ideologías fundamentalistas e intolerantes, gobiernos cobardes, fuerzas de combate ineptas y la conducta de dirigentes que preferían, como el avestruz, esconder la cabeza para no ver el crimen y la paulatina descomposición de nuestra sociedad, Salomón Lerner Febres asumió con integridad verdadera y no poca valentía el encargo más difícil que ha podido encomendarse a peruano alguno: la búsqueda de la verdad de hechos difusos y confusos, enmascarados y escondidos o falseados para ser rebajados o magnificados. Una época en que todos los peruanos fuimos los perdedores absolutos de la humanidad.

Encargo difícil digo, porque, hay que reconocerlo con un mínimo de valentía en nuestras almas: todos fuimos culpables. No existe nadie en este recinto que pueda lanzar la primera piedra de su inocencia. Los peruanos actuamos durante largos años rebajados al grado de zoológico ya fuera apretando el gatillo o en la inacción de la vida burguesa, aposentados en la mullida comodidad de nuestros propios intereses. El egoísmo señoreó olvidados los mínimos principios de la solidaridad humana. La sociedad peruana, pues, fue durante dos décadas removida hasta su hondura, fracturada y destrozada tanto física como moralmente. En ella afloraron todos nuestros problemas que no quisimos o no supimos resolver desde 1920 hacia adelante y agudizados, sin lugar a dudas, por las ineptas dictaduras entronizadas en el poder durante largos años.

El Informe Final de la Comisión de la Verdad fue para muchos motivo de escándalo y rasgamiento de vestiduras, cuando no de interesados ataques de instituciones afectadas para las que les era insoportable contemplar el resplandor de la verdad. Creo que en el Perú nunca se ha visto a tantos culpables reclamando por la inocencia que no supieron o no pudieron conservar. En el Perú Republicano siempre han existido instituciones y personas con la nostalgia por la mediocridad Colonial, por eso verdades como la frase lapidaria de Manuel González Prada de que el Perú es «un organismo enfermo, donde se aplica el dedo brota la pus», más que como una verdad irrefutable, ha sonado siempre para muchos como un insulto injustificado. La verdad, no cabe duda, es con frecuencia dolorosa. 
El inolvidable discurso pronunciado por Salomón Lerner Febres el día de la entrega del Informe Final al Presidente de la República, se trata de una de las piezas oratorias más conmovedoras que me ha sido dado escuchar durante el transcurso de mi vida. No podía ser de otro modo porque su materia se alimenta con el triste testimonio de la sangre derramada por nuestros compatriotas. Este discurso, que removió las fibras más recónditas de los peruanos, es uno de aquellos que habrán de quedar en nuestra Historia y en nuestra Literatura: en él, Salomón Lerner Febres supo no solo revelar las características de la enfermedad de nuestra sociedad sino también indicar el remedio para nuestra redención que, por desgracia, hasta el momento presente no se cumple.

Al incorporar a Salomón Lerner Febres como uno de los suyos, la Academia Peruana de la Lengua cumple con uno de sus fines esenciales pues gana a un intelectual de probada dedicación al trabajo académico, a la enseñanza y a la difusión de la cultura, a un filósofo en quien también se dan las dotes de destacado y sensible escritor, al igual que a una persona que, con sus actos y su conducta ejemplares, ha sabido avalar una moralidad a toda prueba que ahora, como pares suyos en esta comunidad, nos colma de orgullo.

Muchas gracias 
